\title{
Evaluation of internal control genes for quantitative realtime PCR analyses for studying fruit development of dwarf tomato cultivar 'Micro-Tom'
}

\author{
Seung-won Choi ${ }^{1, \dagger}$, Ken Hoshikawa ${ }^{2, \dagger}$, Satoshi Fujita ${ }^{3}$, Dung Pham Thi ${ }^{3}$, \\ Tsuyoshi Mizoguchi ${ }^{1}$, Hiroshi Ezura ${ }^{2}$, Emi Ito ${ }^{1, *}$ \\ ${ }^{1}$ Department of Natural Sciences, International Christian University (ICU), 3-10-2 Osawa, Mitaka, Tokyo 181-8585, Japan; \\ ${ }^{2}$ Faculty of Life and Environmental Sciences, University of Tsukuba, 1-1-1 Tennodai, Tsukuba, Ibaraki 305-8572, Japan; \\ ${ }^{3}$ Graduate School of Life and Environmental Sciences, University of Tsukuba, 1-1-1 Tennodai, Tsukuba, Ibaraki 305-8572, \\ Japan \\ *E-mail: itoemi@icu.ac.jp Tel: +81-422-33-3244 Fax: +81-422-33-1449
}

Received April 19, 2018; accepted May 25, 2018 (Edited by M. Yamaguchi)

\begin{abstract}
Quantitative real-time PCR (qRT-PCR) is widely used to analyze the expression profiles of the genes of interest. In order to obtain accurate quantification data, normalization by using reliable internal control genes is essential. In this study, we evaluated the stability and applicability of eight internal control gene candidates for analyzing gene expression during fruit development in dwarf tomato cultivar Micro-Tom. We collected seventeen different samples from flowers and fruits at different developmental stages, and estimated the expression stability of the candidate genes by two statistical algorithms, geNorm and NormFinder. The combined ranking order and qRT-PCR analyses for expression profiles of SIYABBY2a, SLYABBY1a, FRUITFULL1 and APETALA2c suggested that EXPRESSED was the most stable and reliable internal control gene among the candidates. Our analysis also suggested that RPL8 was also suitable if the sample group is limited to fruits at different maturation stages. In addition to EXPRESSED, GAPDH was also applicable for relative quantitation to monitor gene expression profiles through fruit development from pistil to pericarp.
\end{abstract}

Key words: fruit development, internal control gene, Micro-Tom, qRT-PCR, reference gene.

\section{Introduction}

Quantitative real-time polymerase chain reaction (qRTPCR) is one of the valuable and powerful tools for rapid detection and quantification of gene expressions (Bustin 2000, 2002). qRT-PCR promises high specificity, sensitivity, and reproducibility, and precisely detects the changes in gene expressions in a broad range of species, and various tissue samples collected under different experimental conditions (Gachon et al. 2004). Meanwhile, in order to obtain appropriate and reliable results by qRT-PCR, it is necessary to select the optimal methods to normalize the data you gained (Brunner et al. 2004; Bustin 2002; Freeman et al. 1999). This is because the qualities and quantities of RNA among the samples can easily be altered by the differences in amount of samples collected, transcriptional activities and RNA integrities in individual tissues or cells, recovery rate of RNA, or efficiency of cDNA synthesis for each experiment, and such fluctuations can influence the polymerase chain reactions. There are several ways to conquer such problems, yet the most common and simple method is to apply relative quantitation that normalizes the expression levels of the genes of interest by that of internal control genes (Libus and Štorchová 2006; Thellin et al. 1999). To apply relative quantitation, it is necessary to select rational internal control genes. The usage of inadequate and unstable control genes may cause misunderstandings in expression patterns and relative changes in gene expression, and may mask small differences of gene expressions. Thus, the suitable internal control genes should be expressed constantly and stably in all tissues or cells at every developmental stages irrespective of environmental factors, such as biotic and abiotic stresses (Huggett et al. 2005; Løvdal and Lillo 2009), otherwise multiple internal control genes need to be employed to meet the criteria (Thellin et al. 1999; Vandesompele et al. 2002). Housekeeping

Abbreviations: AP2c, APETALA2c; Cq, quantitation cycle; FUL1, FRUITFULL1; NTC, no template controls; qRT-PCR, Quantitative real-time PCR.

${ }^{\dagger}$ These authors contributed equally to this work.

This article can be found at http://www.jspcmb.jp/

Published online July 24, 2018 
genes, which are essential to maintain the homeostasis of cellular activities, are often used as internal control genes in many qRT-PCR experiments, however, the expressions of several housekeeping genes are known to fluctuate under different experimental conditions (Czechowski et al. 2005; Gutierrez et al. 2008; Thellin et al. 1999). Therefore, it is prerequisite for one to confirm the expression stabilities of the internal controls in prior to the experiments, even if housekeeping genes that seemed to be indispensable for biological activities are chosen for normalization.

Tomato (Solanum lycopersicum) is an important crop in terms of agronomic and economic values in the world. After disclosure of tomato genome information in 2012, tomato researches have rapidly developed, and various reports are being published in recent years (The tomato genome consortium 2012). Numerous tomato cultivars are used for academic researches, while tomato dwarf cultivar Micro-Tom has many experimental advantages. Micro-Tom is a suitable model tomato cultivar, because it is small in size, short in life cycle, and easy to cross with other tomato species. In terms of qRT-PCR analysis in tomato, several internal controls have been examined and reported for some cultivars, such as S. lycopersicom cv. Moneymaker, Ciliegia, Suzanne and commercial variety ACE (Argyropoulos et al. 2006; Dekkers et al. 2012; Expósito-Rodríguez et al. 2008; Løvdal and Lillo 2009). Meanwhile, to our knowledge, there is only one report examining for the suitable internal control genes during the fruit development in Micro-Tom (González-Aguilera et al. 2016).

In this study, to validate optimal internal control genes to analyze tissue-specific gene expression patterns during the development of reproductive organs in MicroTom by qRT-PCR, we selected eight housekeeping genes as internal control gene candidates, and tested for stability and appropriateness for normalization. We collected samples not only from the developing fruits, as in previous reports, but also samples from the developing flowers (pistil and stamen) and a vegetative tissue (leaf). We also collected the pericarp and the gels including the seeds, separately, and examined the stability of the candidate genes in these tissues. By using geNorm and NormFinder algorithms (Andersen et al. 2004; Vandesompele et al. 2002), we evaluated the gene stability, and then analyzed the expression profile of SIYABBY2a, SIYABBY1a, FRUITFULL1 (FUL1) and APETALA2c (AP2c) by using our candidates. Our data suggests that EXPRESSED and TIP41 are suitable internal controls to analyze gene expressions at least in the seventeen different samples we collected. Yet TIP41 was relatively unstable in mature red fruits, thus when performing qRT-PCR analysis in developing fruits, multiple internal controls, including GAPDH or RPL8, are needed to be employed to accurately evaluate the expression profile of gene of interest.

\section{Materials and methods}

\section{Plant materials and growth conditions}

Tomato S. lycopersicum cv. "Micro-Tom" (TOMJPF0001) plant, which is the dwarf cultivar, was used in all experiments (Saito et al. 2011; Shikata et al. 2016). Seeds of these plants were kept on filter papers for germination in a contained plant cultivation room maintained at $25^{\circ} \mathrm{C}, 16 \mathrm{~h} / 8 \mathrm{~h}$ (light/dark), and $300 \mu \mathrm{mol} \mathrm{m}^{-2} \mathrm{~s}^{-1}$. After 1 week, germinated seedlings were transferred to hydroculture media Rockwool cubes (Grodan) applying with a nutrient solution Otsuka 1 Gou and 2 Gou (OAT Agrio Co., Ltd. Tokyo, Japan).

\section{Sampling on whole tomato developmental stages}

Total of 17 samples from different tissues of different developmental stages were collected (Figure 1). $1 \mathrm{~mm}$ bud, $4.5 \mathrm{~mm}$ bud, and open flowers were prepared as flower samples (Figure 1A). From $4.5 \mathrm{~mm}$ and open flowers, pistil and stamen were collected separately (Figure 1B). Different fruit samples were collected from six different developmental stages of Micro-Tom, namely, " $1 \mathrm{~cm}$ immature green", " $2 \mathrm{~cm}$ immature green", "mature green", "breaker", "orange”, and "mature red". Collected fruits were divided into pericarps (hereafter referred to as "fruits"), and seed/gel, except for $1 \mathrm{~cm}$ fruit (Figure 1C). Leaves were harvested at 30 days after sowing. All samples were immediately frozen in liquid nitrogen, and stored at $-80^{\circ} \mathrm{C}$ until RNA extraction.

\section{RNA extraction and cDNA synthesis}

Total RNA extraction was performed by using the QIAGEN RNeasy Plant Mini Kit (QIAGEN, Hilden, Germany). RNA was quantified using its absorbance at $260 \mathrm{~nm}$. The integrity of RNA was evaluated by $260 \mathrm{~nm} / 280 \mathrm{~nm}$. cDNA was synthesized from $660 \mathrm{ng}$ of total RNA by using ReverTra Ace ${ }^{\circledR}$ qPCR RT Master Mix with gDNA Remover (TOYOBO, Osaka, Japan). Synthesized cDNA was diluted to 10 -folds to be applied for qRT-PCR experiments.

\section{Quantitative Real-Time PCR}

qRT-PCR was performed on 96-wells plates with AriaMx Real-Time PCR system (Agilent, Santa Clara, CA, US). Reactions were prepared in a total volume of $20 \mu \mathrm{l}$ containing: $2 \mu \mathrm{l}$ of template, $0.8 \mu \mathrm{l}$ of each amplification primer sets (final concentration of $200 \mathrm{nM}$ each), $10 \mu \mathrm{l}$ of KAPA SYBR Fast qPCR Master Mix (2x) ROX Low (Kapa Biosystems, Boston, MA, US). The PCR reaction was performed according to the manufacturer's instructions, in brief, $95^{\circ} \mathrm{C}$ for $3 \mathrm{~min}$, followed by 40 cycles of $3 \mathrm{~s}$ at $95^{\circ} \mathrm{C}$ (denature), and $20 \mathrm{~s}$ at $60^{\circ} \mathrm{C}$ (anneal and extension). Melting curve analysis was performed under the following condition: $30 \mathrm{~s}$ at $95^{\circ} \mathrm{C}, 30 \mathrm{~s}$ at $65^{\circ} \mathrm{C}$, and $30 \mathrm{~s}$ at $95^{\circ} \mathrm{C}$. At least three independent experiments were performed by using three biological replicates. Baseline and quantitation cycle $(\mathrm{Cq})$ were automatically calculated by using AriaMX1.2 

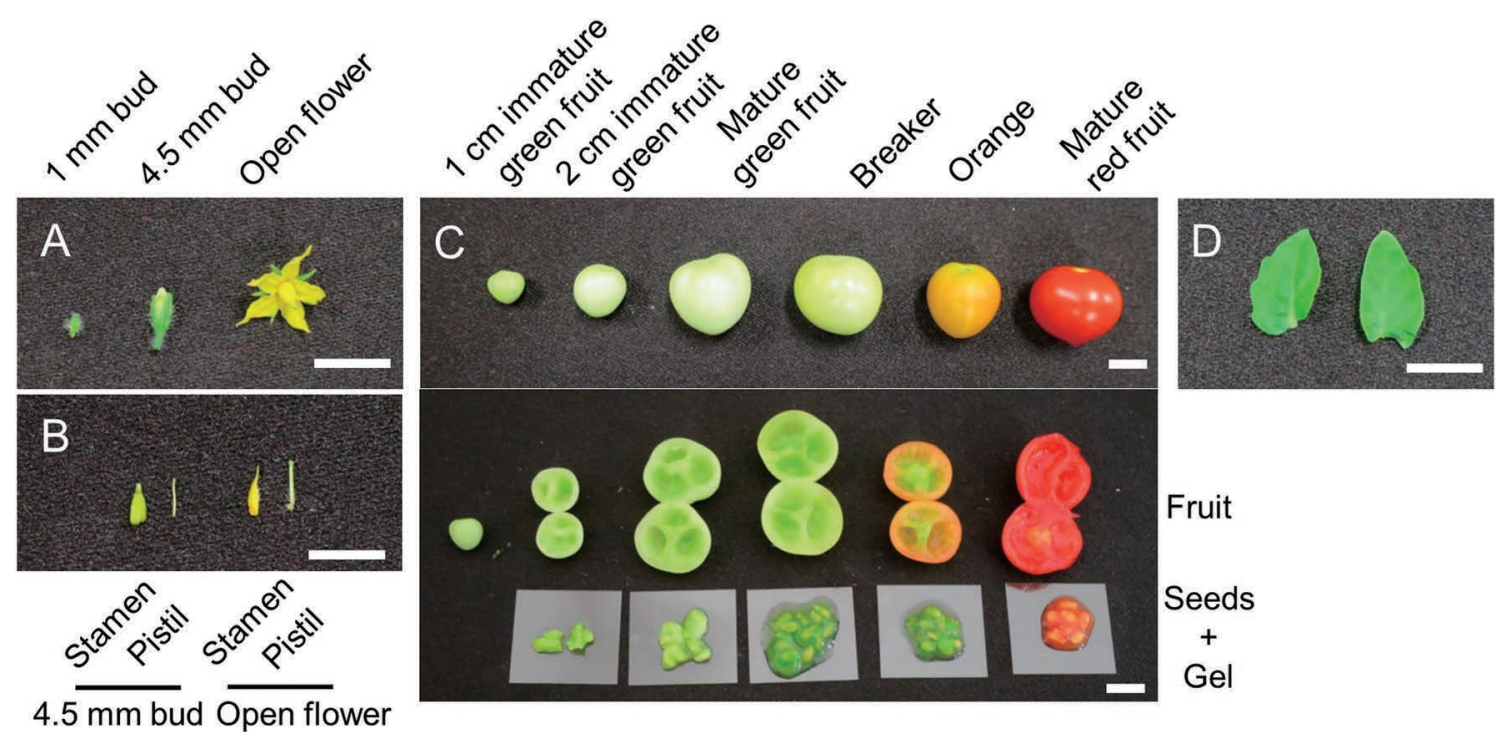

Figure 1. Samples collected for evaluation of internal control gene candidates, and to analyze expression profiles of tissue-specific genes during fruit development in Micro-Tom. Panels show $1 \mathrm{~mm}$ bud, $4.5 \mathrm{~mm}$ bud and open flower (A), pistil and stamen collected from $4.5 \mathrm{~mm}$ bud and open flower (B), individual fruits at different developmental stages (upper panel), and pericarps and seeds/gel portions collected from each stage (lower panel) (C), leaf at 30 days after sowing (D). Bar $=1 \mathrm{~cm}$.

software (Agilent, Santa Clara, CA, US). The primers are constructed as in previous reports (CAC, EXPRESSED, RPL8, SAND and TIP41; Expósito-Rodríguez et al. 2008, ACT and GAPDH; Mascia et al. 2010, PP2a; Czechowski 2005; Hong et al. 2010, FUL1 and AP2c; González-Aguilera et al. 2016), and listed in Table 2. The primer sets to test for SlYABBY1a and SlYABBY $2 a$ expressions were designed in this study, and listed in Table 2. For all primer pairs, amplification specificities were confirmed by melting curve analysis and gel electrophoresis. In brief, the production of single peak was observed by melting curve analysis to confirm the amplification of single DNA fragment under this PCR conditions. Also, the amplicons were amplified using the mixed cDNA samples as template, and loaded onto $2 \%$ agarose gel to confirm for the single bands. The efficiency of PCR reactions was calculated for each primer set by using a dilution series plotted into standard curves.

\section{Evaluation of reference gene stability}

The stability of the candidate internal control genes was evaluated by using geNorm (Vandesompele et al. 2002) and NormFinder (Andersen et al. 2004) statistical algorithms. Cq values were converted into relative quantities by using standard curves, then applied for evaluation. The qBase+ software (Biogazelle, Belgium) was installed for geNorm analysis. NormFinder analysis was performed as a free add-in program for Microsoft Excel.

\section{Results and discussion}

Sampling of reproductive tissues from Micro-Tom and $q R T-P C R$ analysis of internal control gene candidates

To find internal control genes that are constantly and stably expressed in reproductive tissues (flowers and fruits) at different developmental stages of Micro-Tom, we collected 16 different samples from flowers and fruits (Figure 1). For flowers, pistils and stamens were collected separately, because they are the important organs that fertilize and develop into fruits. For fruits, 11 different samples from six different developmental stages were collected. Except for $1 \mathrm{~cm}$ immature green fruits, pericarp (hereafter, referred to as "fruits") and the gel including the seeds were collected separately. As for representative vegetative tissue, 30-day old leaves were collected to check for the genes that are typically expressed in reproductive organs (Figure 1D).

Then, qRT-PCR analysis was performed for $51 \mathrm{cDNA}$ samples (17 samples with 3 biological replicates) by using the primer pairs for eight internal control gene candidates that have been used as reference genes for other studies [CAC, EXPRESSED, RPL8, SAND and TIP41; (Expósito-Rodríguez et al. 2008), ACT and GAPDH; (Mascia et al. 2010), PP2a; (Czechowski 2005; Hong et al. 2010] (Table 1). Melting-curve analysis, and gel electrophoresis indicated that the primer sets listed in Table 2 successfully amplify the single PCR product of the expected size (Supplemental Figures $1,2)$. For the primer sets used to amplify $A C T, R P L 8$, SAND, TIP41 and SlYABBY2a, lower peaks appeared at lower temperatures in controls without templates [no template controls (NTCs); Supplemental Figure 1A, F, $\mathrm{G}, \mathrm{H}, \mathrm{L}]$, and bands corresponding to the nonspecific amplification in NTC appeared in gel electrophoresis analysis (Supplemental Figure 2B). However, such peaks or nonspecific bands were not detectable when template cDNA exists in the reactions. Collectively, the primer sets 
Table 1. Description of candidate control genes and validation genes.

\begin{tabular}{|c|c|c|c|}
\hline Gene symbol & Gene name & Gene ID & Description \\
\hline ACT & Actin-7 & $\begin{array}{l}\text { TMCS03g1005280 } \\
\text { Solyc03g078400.2.1 }\end{array}$ & Actin protein \\
\hline $\mathrm{CAC}$ & Clathrin adaptor complexes medium subunit & $\begin{array}{l}\text { TMCS08g1011650 } \\
\text { Solyc08g006960.2.1 }\end{array}$ & Adaptor protein- $2 \mu$-adaptin \\
\hline EXPRESSED & Expressed sequence & $\begin{array}{l}\text { TMCS07g1013650 } \\
\text { Solyc07g025390.2.1 }\end{array}$ & Uncharacterized protein \\
\hline GAPDH & Glyceraldehyde 3-phosphate dehydrogenase- $\beta$-Tubulin & $\begin{array}{l}\text { TMCS05g1003510 } \\
\text { Solyc05g014470.2.1 }\end{array}$ & Glyceraldehyde-3-phosphate dehydrogenase \\
\hline PP2a & Phosphatase $2 \mathrm{~A}$ regulatory A subunit & $\begin{array}{l}\text { TMCS05g1002050 } \\
\text { Solyc05g009600.2.1 }\end{array}$ & $\begin{array}{l}\text { Serine/threonine-protein phosphatase } 2 \mathrm{~A} 65 \mathrm{kDa} \\
\text { regulatory subunit } \mathrm{A} \beta \text { isoform }\end{array}$ \\
\hline RPL8 & $60 \mathrm{~S}$ ribosomal protein $\mathrm{L} 8$ & $\begin{array}{l}\text { TMCS10g1010670 } \\
\text { Solyc10g006580.2.1 }\end{array}$ & 60 S ribosomal protein L8-like \\
\hline SAND & SAND family & $\begin{array}{l}\text { TMCS03g1010850 } \\
\text { Solyc03g115810.2.1 }\end{array}$ & Vacuolar fusion protein MON1 \\
\hline TIP41 & TIP41-like protein & $\begin{array}{l}\text { TMCS10g1004590 } \\
\text { Solyc10g049850.1.1 }\end{array}$ & TIP41-like protein \\
\hline FUL1 & FRUITFULL1 & $\begin{array}{l}\text { TMCS06g1019990 } \\
\text { Solyc06g069430.2.1 }\end{array}$ & agamous-like MADS-box protein AGL8 homolog \\
\hline $\mathrm{AP} 2 \mathrm{c}$ & APETALA2c & $\begin{array}{l}\text { TMCS02g1013240 } \\
\text { Solyc02g093150.2.1 }\end{array}$ & AP2-like ethylene responsive transcription factor \\
\hline SlYABBY1a & YABBY 1 of Solanum lycopersicum & $\begin{array}{l}\text { TMC01g1027040 } \\
\text { Solyc01g091010.2.1 }\end{array}$ & YABBY-like transcription factor \\
\hline SlYABBY2a & YABBY 2 isoform X2 of Solanum lycopersicum & $\begin{array}{l}\text { TMCS06g1009610 } \\
\text { Solyc06g073920.2.1 }\end{array}$ & YABBY-like transcription factor \\
\hline
\end{tabular}

Table 2. Details of primers of candidate control genes and validation genes and parameters derived from qPCR analysis.

\begin{tabular}{|c|c|c|c|c|c|}
\hline \multirow[t]{2}{*}{ Gene symbol } & \multirow[t]{2}{*}{ Prime Sequence Forward/reverse } & \multicolumn{2}{|c|}{$\begin{array}{l}\text { Amplicon length } \\
\text { (bp)* }\end{array}$} & \multirow[t]{2}{*}{$\mathrm{E}(\%)^{* *}$} & \multirow[t]{2}{*}{$R^{2 * *}$} \\
\hline & & cDNA & gDNA & & \\
\hline ACT & AGGCAGGATTTGCTGGTGATGATGCT/ATACGCATCCTTCTGTCCCATTCCGA & 107 & 107 & 102.27 & 0.982 \\
\hline CAC & CCTCCGTTGTGATGTAACTGG/ATTGGTGGAAAGTAACATCATCG & 173 & 592 & 95.88 & 0.992 \\
\hline EXPRESSED & GCTAAGAACGCTGGACCTAATG/TGGGTGTGCCTTTCTGAATG & 183 & 291 & 91.7 & 0.996 \\
\hline GAPDH & GGCTGCAATCAAGGAGGAA/AAATCAATCACACGGGAACTG & 204 & N/A & 94.22 & 0.998 \\
\hline PP2a & TGGCAAAGGTGTTGCAATCC/CTTTCCСCTTTTGCTTCTTCGTG & 266 & 450 & 99.57 & 0.996 \\
\hline RPL8 & CCGAAGGAGCTGTTGTTTGTA/ACCTGACCAATCATAGCACGA & 184 & 1091 & 101.89 & 0.994 \\
\hline SAND & TTGCTTGGAGGAACAGACG/GCAAACAGAACCCCTGAATC & 164 & 3559 & 107.09 & 0.989 \\
\hline TIP41 & ATGGAGTTTTTGAGTCTTCTGC/GCTGCGTTTCTGGCTTAGG & 235 & $\mathrm{~N} / \mathrm{A}$ & 99 & 0.995 \\
\hline FUL1 & GTTTTGCCACAACAACTGGACTC/CTTGCTGCTGTGAAGAACTACC & 106 & 1124 & 98.94 & 0.997 \\
\hline $\mathrm{AP} 2 \mathrm{c}$ & CCGTTTCGAATTCAAGTTCA/ACCCAGACCCACCATAGAGA & 122 & 122 & 107.25 & 0.981 \\
\hline SlYABBY1a & ACCCAAATGAATCACTCATGCCA/CTTTGATACGTTGGATCTCGTCCT & 144 & N/A & 104.04 & 0.985 \\
\hline SlYABBY2a & TCTGCAGCACAATTCTTGCG/AATTTGCGCAGTGTCCACAC & 84 & 2346 & 102.8 & 0.988 \\
\hline
\end{tabular}

*Estimated form Micro-Tom cDNA/gDNA sequences in TOMATOMICS (http://bioinf.mind.meiji.ac.jp/tomatomics/index.php). ** Mean of 3 biological replicates, N/A = Non-amplified.

used in this study are applicable for qRT-PCR analysis.

\section{Schemes to select stable internal control gene candidates}

The data obtained by qRT-PCR were subjected to evaluate the expression stability of the candidate genes among the samples we collected. In prior to the analysis, the entire $\mathrm{Cq}$ datasets were converted to relative quantity values by using the calibration curves. Then, two representative algorithms, geNorm and NormFinder, were applied (Andersen et al. 2004; Vandesompele et al.
Table 3. Pairwise variation analysis of control genes by geNorm analysis. The $V_{2 / 3}$ values from all our datasets were below the cut off value of 0.15 , indicating that two stable reference genes determined by geNorm are necessary for a reliable normalization.

\begin{tabular}{lllll}
\hline & All & Fruit & Flower & Seed/gel \\
\hline $\mathrm{V}_{2 / 3}$ & $\underline{\mathbf{0 . 1 0 3}}$ & $\underline{\mathbf{0 . 0 7 4}}$ & $\underline{\mathbf{0 . 0 6 3}}$ & $\underline{\mathbf{0 . 1 4 7}}$ \\
$\mathrm{V}_{3 / 4}$ & 0.114 & 0.049 & 0.08 & 0.1 \\
$\mathrm{~V}_{4 / 5}$ & 0.116 & 0.058 & 0.078 & 0.116 \\
$\mathrm{~V}_{5 / 6}$ & 0.16 & 0.072 & 0.07 & 0.119 \\
$\mathrm{~V}_{6 / 7}$ & 0.147 & 0.059 & 0.118 & 0.114 \\
$\mathrm{~V}_{7 / 8}$ & 0.119 & 0.066 & 0.175 & 0.128 \\
\hline
\end{tabular}



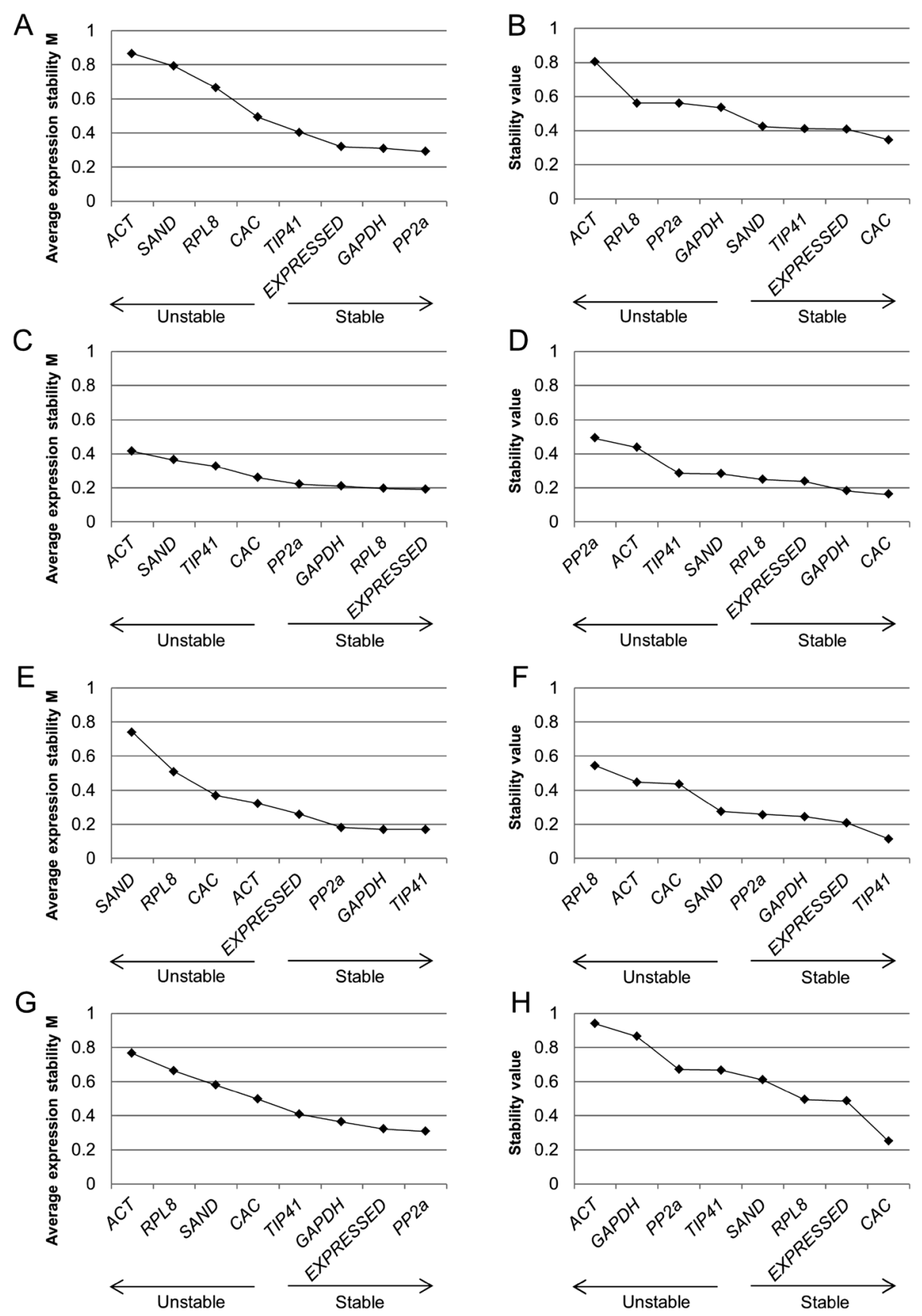

Figure 2. Expression stability of control genes evaluated by geNorm (A, C, E and G) and NormFinder (B, D, F and H) for all datasets (A and B), fruit dataset $(\mathrm{C}$ and $\mathrm{D})$, flower dataset $(\mathrm{E}$ and $\mathrm{F})$ and seed/gel dataset $(\mathrm{G}$ and $\mathrm{H})$. In both analyses, lower values indicate higher stability of the genes. Candidate genes were arranged in the order of the stability on the $\mathrm{X}$-axis.

2002). These algorithms are used to rate the constancy of expressions among samples (Lacerda et al. 2015; Mascia et al. 2010; Müller et al. 2015). The geNorm analysis run by $\mathrm{qBase}+$ software computes an expression stability values $(\mathrm{M})$ for tested genes, as the average pairwise variation among candidates (Vandesompele et al. 2002). The pairwise variation value $\left(\mathrm{V}_{n / n+1}\right)$ suggests for the minimum number of internal control genes employed for normalizations. The pairwise analysis using our datasets indicated that at least two internal control genes should be employed for reliable normalizations (Table
3). NormFinder also calculates stability values for each candidates (Andersen et al. 2004). NormFinder enables grouping of the samples, and calculates the intra- and intergroup variation of candidate genes, and suggests suitable internal control gene. Our data indicated that all candidate genes displayed stability values below 1.5 , suggesting for the housekeeping functions of the selected genes (Mascia et al., 2010; Lacerda et al., 2015; Müller et al., 2015) (Figure 2A, B). Meanwhile, the stability values output by geNorm and NormFinder analyses were distinctive for each candidate. For example, $P P 2 a$, which 
was characterized as the most stable gene by geNorm analysis, was ranked to 6 th (less stable) by NormFinder analysis (Figure 2A, B). Likewise $C A C$, which was suggested as a good reference gene in other studies (Expósito-Rodríguez et al. 2008; González-Aguilera et al. 2016), was classified as the most stable gene by NormFinder analysis, but less stable gene (5th from the most stable) by geNorm analysis (Figure $2 \mathrm{~A}, \mathrm{~B}$ ). On the other hand, EXPRESSED was ranked as highly stable gene by both analysis. Therefore, we arbitrary grouped the first four genes that were ranked stable by geNorm and NormFinder analyses, and extracted the ones that were commonly classified as highly stable genes by both algorithms (Figure 3). Similarly, we grouped the last four genes that were indicated as less stable, and characterized them as "unstable genes". Table 4 summarizes the results deduced from this classification schemes. Our results indicated that EXPRESSED and TIP41 were grouped into "stable" genes, whereas ACT and RPL8 were classified as "unstable" genes, when qRT-PCR data obtained from all samples (17 different samples with three biological replicates) were subjected for this classification scheme

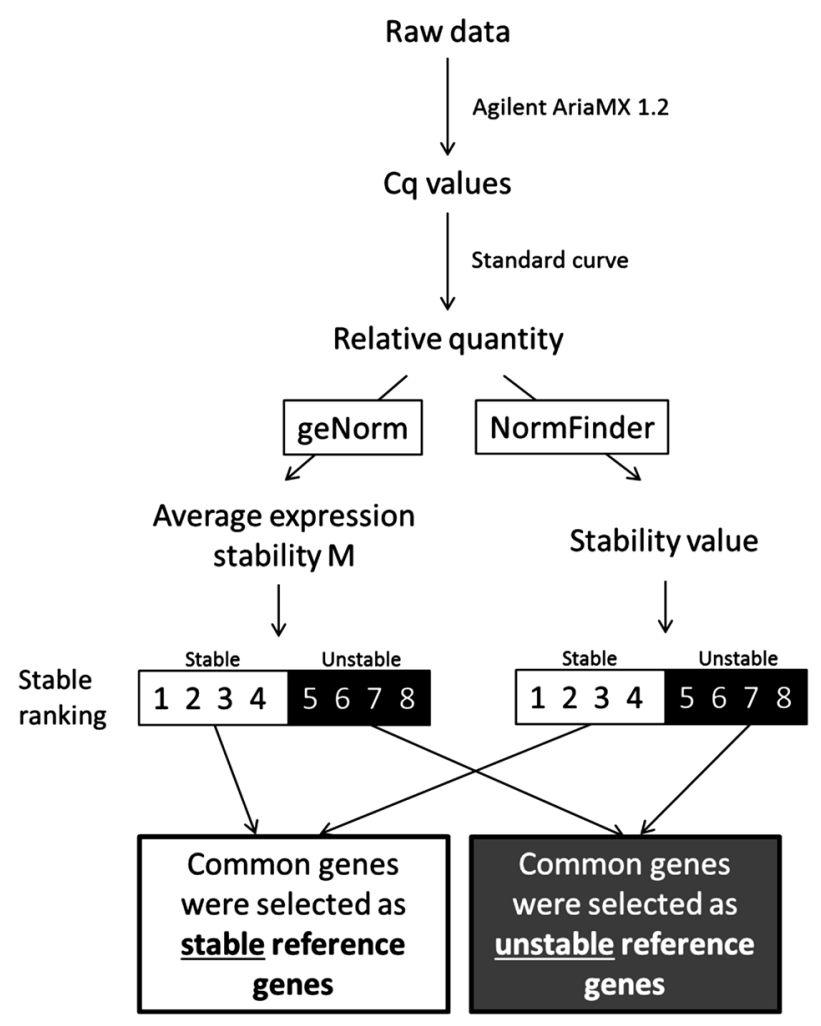

Figure 3. Schemes for combined ranking order. Flow chart represents how the stable and unstable genes were selected in this study.
(Table 4).

To see if the optimal candidate genes differ among the tissues, we also classified the candidate genes separately by using datasets only including fruit samples (Figure 2C, D), flower samples (Figure 2E, F), and seed/gel samples (Figure 2G, H). As a result, EXPRESSED was classified as the stable gene for every sample groups we analyzed, however, TIP41 was classified as unstable gene for analyzing fruit samples (discussed later), whereas RPL8 was classified as "unstable" among flower samples, but "stable" for the group including only the fruits samples (Table 4). GAPDH could also be a stable internal control gene candidate, when analyzing and comparing gene expression in developing flowers and fruits. Also, PP2a can be employed for normalization when analyzing samples from developing flowers. EXPRESSED was the only "stable" internal control candidate for the group including seed/gel samples.

\section{Application of "stable" and "unstable" internal control gene candidates to relative quantitation of gene expressions}

To validate the applicability of the selected internal control genes listed in Table 4, we performed further qRT-PCR analysis to see the expression profiles of genes that are specifically expressed during fruit and flower developments (Tables 1 and 2). For this purpose, the expressions of SlYABBY2a, SlYABBY1a, FUL1 and AP2c were analyzed by qRT-PCR, and normalized by using the "stable" and "unstable" internal control gene candidates. $Y A B B Y s$ encode for the transcription factors which possess $\mathrm{Cys}_{2} \mathrm{Cys}_{2}$ zinc finger domain and helix-loop-helix motif termed YABBY domain (Golz and Hudson 1999). In Arabidopsis thaliana, INO and CRC are reported as the reproductive $Y A B B Y s$ expressed specifically in pistils (Alvarez and Smyth 1999; Villanueva et al. 1999). Tomato has nine YABBY genes and eight of which $(S l C R C a$, SlCRCb, SlINO, SlYABBY1a, SlYABBY1b, SlYABBY2a, $F A S / S l Y A B B Y 2 b$ and SlYABBY5a) are expressed in floral organs (Ezura et al. 2017; Huang et al. 2013). SlYABBY2a and SlYABBY1a show notable expression profiles in developing pistils and stamens. The RNA-seq analysis indicated that SlYABBY $2 a$ was expressed in wide range of floral organs including pistils, stamens, petals, and sepals, and its expression was also monitored in mature green and red fruits (Ezura et al. 2017). In pistils, the expression level of SlYABBY2a was shown to elevate, and reached the highest at 7-day-after-flowering stage. Its expression was maintained in mature green fruit stage,

Table 4. List of stable and unstable internal control genes among different datasets.

\begin{tabular}{lcccc}
\hline & All & Fruit & Flower & Seed/gel \\
\hline Stable & EXPRESSED TIP41 & EXPRESSED GAPDH RPL8 & TIP41 GAPDH EXPRESSED PP2a & EXPRESSED \\
Unstable & ACT RPL8 & ACT SAND TIP41 & SAND RPL8 CAC ACT & ACT \\
\hline
\end{tabular}



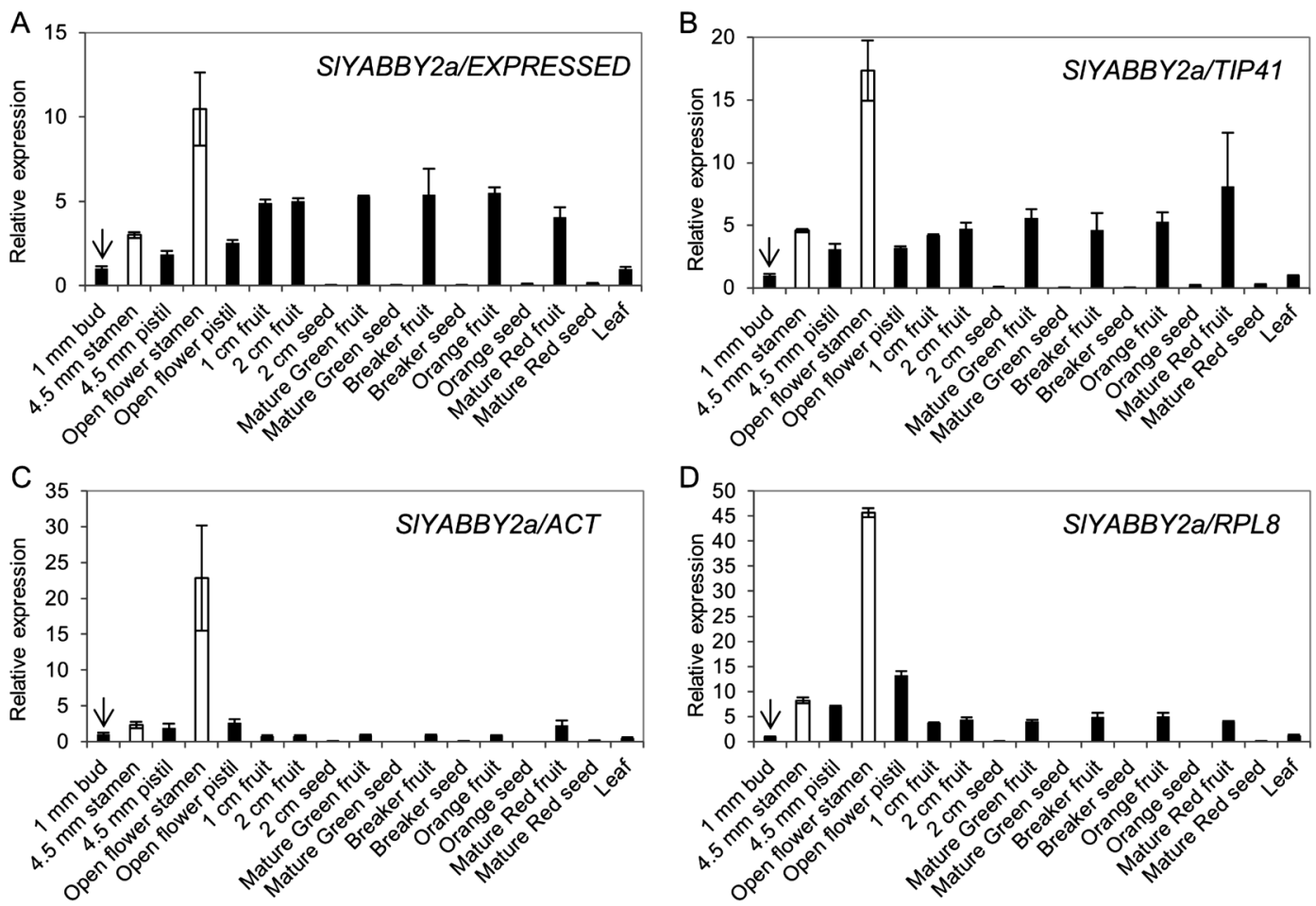

Figure 4. Expression profiles of SlYABBY2a normalized with stable genes (EXPRESSED; A, TIP41; B) and unstable genes (ACT; C and RPL8; $D$ ). For the relative representation, the expression levels at " $1 \mathrm{~mm}$ bud" stage (arrows) were adjusted to 1 . White bars indicate the expression of $S I Y A B B Y 2 a$ in stamens. Error bars represent the standard error of the mean.

and decreased in red fruit stage (Ezura et al. 2017). In comparison to SlYABBY2a, SlYABBY1a is predominantly expressed in floral organs. The expression of SlYABBY1a in pistils was kept high before flowering, and then decreased after anthesis, whereas its expression level in the stamen was elevated after anthesis (Ezura et al. 2017).

To compare the expression profiles normalized by different internal control gene candidates, we firstly performed relative quantitation of SlYABBY2a expressions. The RNA-seq analysis indicated that there were approximately 2 -folds differences in SlYABBY2a expression between young pistils in 1-2 $\mathrm{mm}$ bud and mature green fruit (Ezura et al. 2017). When we normalized the expression level of SIYABBY2a against EXPRESSED and TIP41, the stable internal control gene candidates, the fold-changes in SlYABBY2a expression from " $4.5 \mathrm{~mm}$ pistil" to "mature green fruit" stages were 2.8-folds for SlYABBY2a/EXPRESSED (Figure $4 \mathrm{~A}$ ) and 1.8 -folds for SlYABBY2a/TIP41 (Figure 4B). On the other hand, when SlYABBY2a expression was normalized against ACT (Figure 4C) and RPL8 (Figure $4 \mathrm{D})$, the unstable internal control gene candidates, its expression looked as though it was decreased during development. The fold-changes in SlYABBY2a expression from " $4.5 \mathrm{~mm}$ pistil" to "mature green fruit" stages were 0.45-folds for SlYABBY2a/ACT (Figure 4C), and 0.59 -folds for SlYABBY2a/RPL8 (Figure 4D). The expression level of $S l Y A B B Y 2 a$ in stamens is reported to elevate by approximately 3 -folds upon flowering
(Ezura et al. 2017). Our data indicated that the fold changes in relative expression levels of SlYABBY2a in stamens collected from $4.5 \mathrm{~mm}$ bud (" $4.5 \mathrm{~mm}$ stamen") and open flower ("open flower stamen") were 3.5 -folds for SlYABBY2a/EXPRESSED (Figure 4A), and 3.8-folds for SlYABBY2a/TIP41 (Figure 4B). However, when the expression of SlYABBY2a was normalized against $A C T$ (Figure 4C) and RPL8 (Figure 4D), the fold differences in their expressions were 9.9-times and 5.6-times, respectively.

Similarly, plausible expression profiles of SlYABBY1a were obtained by using stable internal control gene candidates. When we normalized the expression level of SlYABBY1a against our candidates, the increase in expression levels from " $4.5 \mathrm{~mm}$ stamen" to "open flower stamen" were 3.6-folds for SLYABBY1a/EXPRESSED (Supplemental Figure 3A), and 3.9-folds for SlYABBY1a/TIP41 (Supplemental Figure 3B), whereas 10.2-folds for SlYABBY1a/ACT (Supplemental Figure 3C), and 5.6-folds for SlYABBY1a/RPL8 (Supplemental Figure 3D). It has been demonstrated that SlYABBY1a, expressions were increased by approximately 2 -folds in stamens (Ezura et al. 2017), thus our data imply that the expression levels of genes in open flower stamen are overestimated when normalized against unstable reference genes.

We further evaluated our internal control gene candidates by analyzing the expression profiles of fruit specific genes, FUL1 and AP2c. FUL1 is a homolog of 
the Arabidopsis MADS domain transcription factor FUL (Bemer et al. 2012). In tomato cultivar Micro-Tom and MT-Rg1, the FUL1 expression in fruit is relatively low at immature stages, but gradually increases as the fruit develops and ripens (Bemer et al. 2012; GonzálezAguilera et al. 2016). FUL1 was also reported to be expressed in the stamens at lower level (Hileman et al. 2006). AP2c was identified as a homolog of Arabidopsis $A P 2$, a member of the AP2/ETHYLEN REPONSE FACTOR (ERF) transcription factor superfamily that is involved in ethylene biosynthesis and signaling (Karlova et al. 2011). AP2c is highly expressed in flowers at anthesis and in immature green fruits, and then its expression level decreases in mature fruits (González-Aguilera et al. 2016; Karlova et al. 2011). When FUL1 was normalized against EXPRESSED (Supplemental Figure 4A) and TIP41 (Supplemental Figure 4B), we could monitor maturation stage-dependent increase in expression during the course of fruit development and ripening. However, the relative expression level of FUL1 appeared to be 2.3-folds higher for FUL1/TIP41 compared to FUL1/EXPRESSED at mature red fruits stage (discussed later). We could also see the expression of FUL1 in stamen collected from the open flowers. However, unlike the previous report (Bemer et al. 2012), the relative expression of FUL1 in open flower stamen appeared to be the highest in open flower stamen, when the datasets were normalized against the unstable internal gene candidates (Supplemental Figure $4 \mathrm{C}, \mathrm{D})$. In comparison to expression level in "open flower stamen", the FUL1 expressions appeared to be 2- and 2.2-folds higher than that in "mature red fruit" stage when normalized against ACT (Supplemental Figure 4C) and RPL8 (Supplemental Figure 4D), respectively. Likewise, the expressions of $A P 2 c$ in open flower stamens were overextrapolated, when their expressions were normalized against ACT and RPL8 (Supplemental Figure 5).

\section{EXPRESSED and RPL8 are suitable internal control genes for qRT-PCR analysis in developing fruits}

Interestingly, TIP41 was classified as "stable" internal control to analyze 17 different samples we employed in this study, but classified to "unstable" gene when we limit the sample groups to fruits (Table 4). Contrarily, RPL8 was evaluated as "stable" gene among the fruit sample sets (Table 4). Thus, we finely examined the validity of TIP41 and RPL8, as well as EXPRESSED and $A C T$, for qRT-PCR analysis using datasets collected from developing fruits (Figure 5). When the expression of FUL1 was normalized against EXPRESSED (Figure $5 \mathrm{~A}$ ) and RPL8 (Figure 5B), we could monitor the developmental stage-dependent increase in FUL1 as reported previously (Bemer et al. 2012; GonzálezAguilera et al. 2016). Notably, the expression level of FUL1 was reported to double from "mature green fruit" to "breaker" stages, then reached the maxima at mature red fruits stage (Bemer et al. 2012; González-Aguilera et al. 2016). Normalization either by stable and unstable internal control gene candidates indicated such an increase in FUL1 expression from "mature green fruit" to "breaker" stages (Figure 5A to D; EXPRESSED; 2.0-folds, RPL8; 2.4-folds, TIP41; 1.7-folds and ACT; 2.1-folds). However, when FUL1 expression was normalized against TIP41 (Figure 5C) and ACT (Figure 5D), the expression levels of FUL1 at mature red fruit stage appeared to be elevated by 6.6- and 13.9-times, respectively, compared to 3.9-folds for FUL1/EXPRESSED and 4.7-folds for FUL1/RPL8 (Figure 5A, B).

Previous reports indicated that the expression of $A P 2 c$ was gradually lost as the fruit matures and ripens (González-Aguilera et al. 2016; Karlova et al. 2011). Such expression profiles were prominent when $A P 2 c$ expression was normalized against EXPRESSED (Figure $5 \mathrm{E}$ ) and RPL8 (Figure 5F). On the other hand, when $A P 2 c$ expression was normalized against TIP41 (Figure $5 \mathrm{G}$ ) and $A C T$ (Figure 5H), AP2c expression appeared to decrease from " $1 \mathrm{~cm}$ fruit" to "mature red fruit" stages only by 4.9 - and 2.8-folds, respectively, compared to 10.1-folds for AP2c/EXPRESSED (Figure 5E), and 7.6-folds for AP2c/RPL8 (Figure 5F). Collectively, our results suggest that the expression levels of the target genes may be overestimated especially in "mature red fruit" stages if unstable internal control genes are utilized for normalization. Our data also suggests that EXPRESSED and RPL8 are good internal controls when performing qRT-PCR analysis of the target genes only in developing fruits.

\section{EXPRESSED and GAPDH are ideal internal control genes for $q R T-P C R$ analysis when comparing} gene expressions in developing fruits and flowers

Pistils and stamens are important reproductive tissues that develop into fruits, thus the gene expressions in floral organs often need to be monitored in comparison to that in developing fruits. By our classification, EXPRESSED and GAPDH were found to be the "stable" internal control gene candidates among fruits and flower datasets (Table 4). To test whether these candidates could be the ideal internal controls for qRT-PCR analysis monitoring expression profiles in developing flowers and fruits simultaneously, we performed relative quantitation of SIYABBY $2 a$ expressions to EXPRESSED and GAPDH. According to the recent report, the expression of SIYABBY $2 a$ in female reproductive tissues is kept high in pistils, especially in 7 days after flowering, until mature green fruit stage, then decreased to red fruit stage (Ezura et al. 2017). Such an expression profile was reproduced when SIYABBY $2 a$ was normalized against EXPRESSED (Figure 6A) and GAPDH (Figure 6B). When the expression of SlYABBY2a was normalized against TIP41 
A

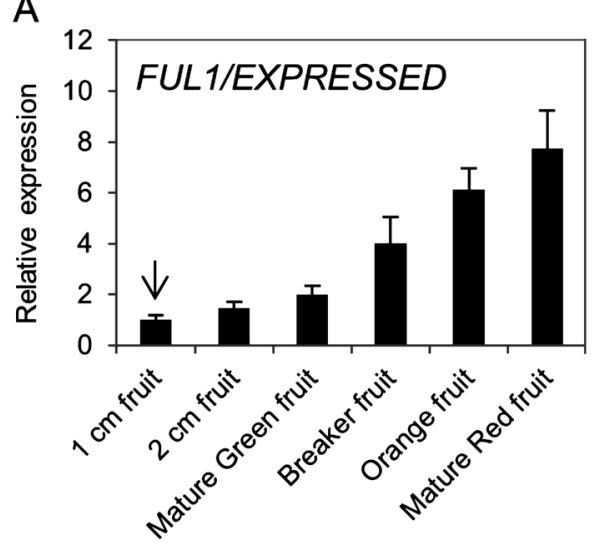

C
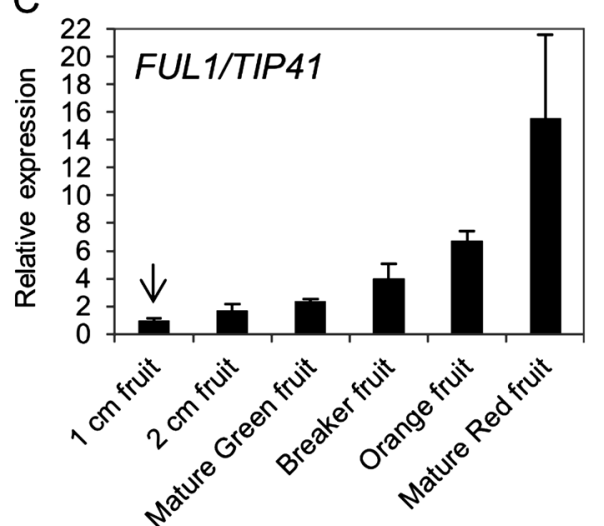

E
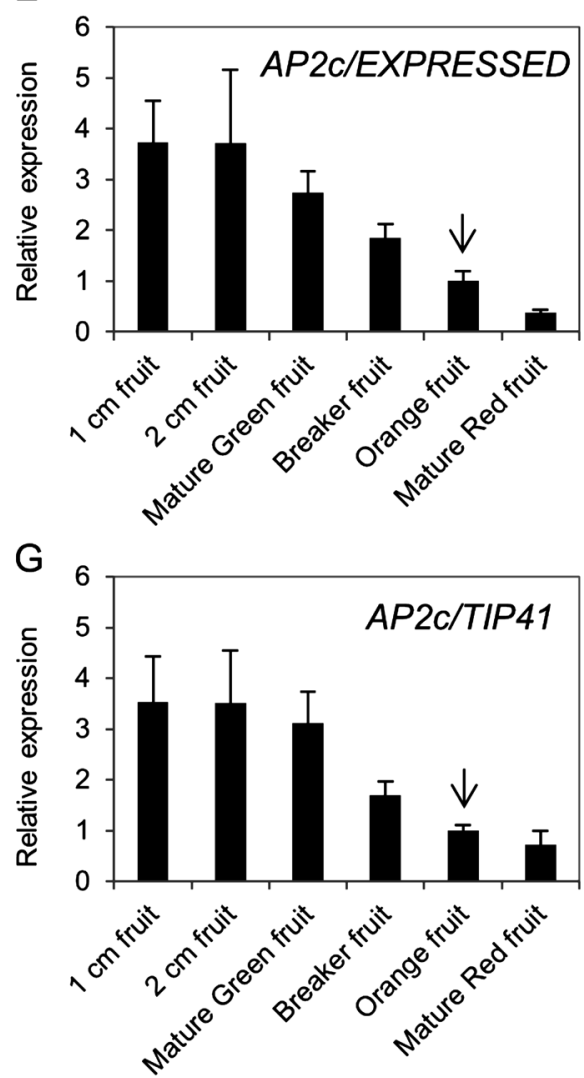

B

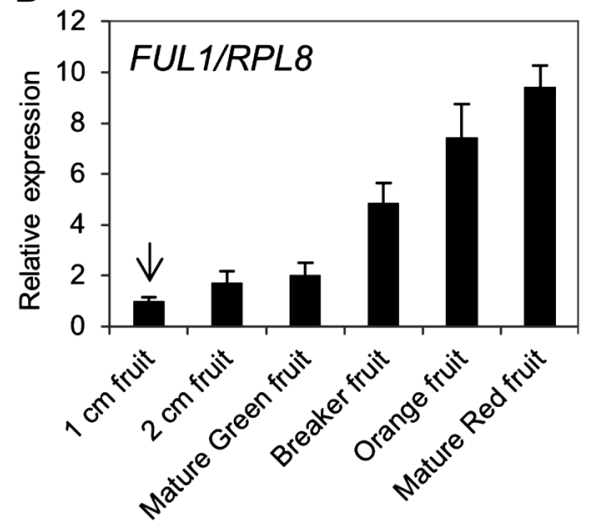

D

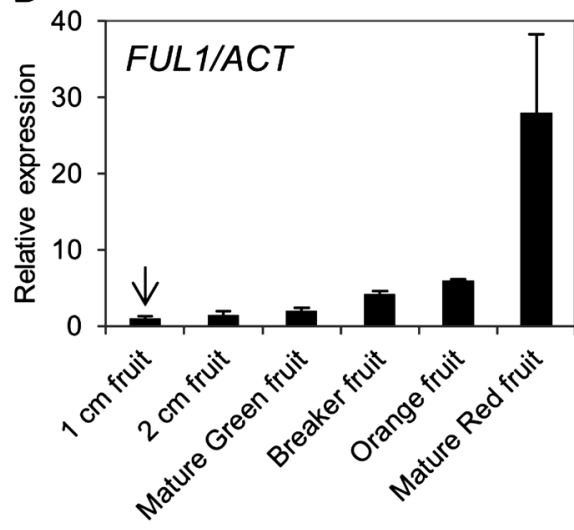

F
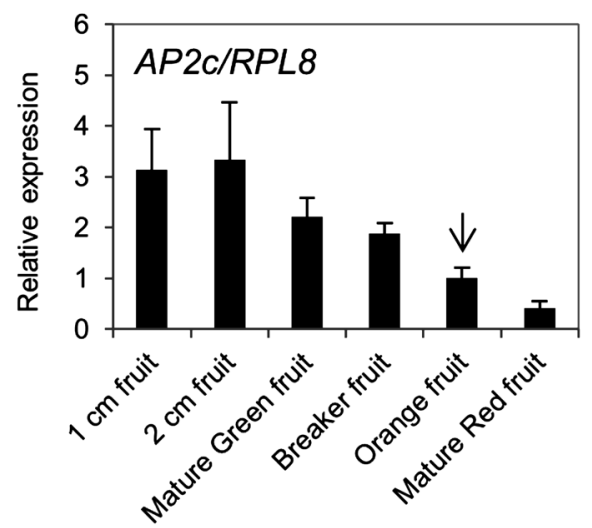

$\mathrm{H}$

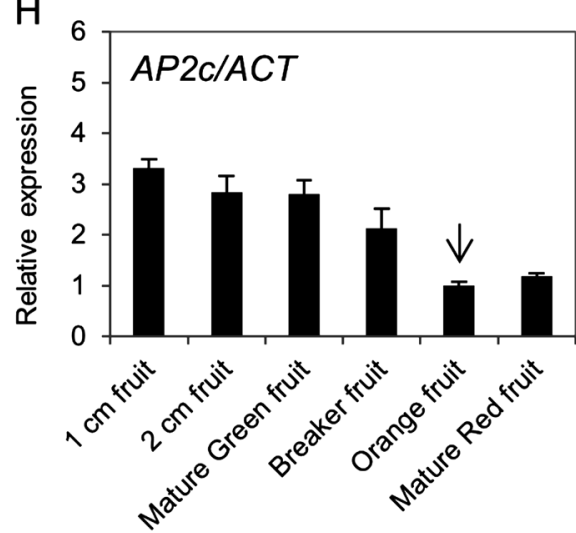

Figure 5. Expression profiles of FUL1 (A to D) and AP2c (E to H) in developing fruits normalized against EXPRESSED (A and E), RPL8 (B and F), TIP41 (C and $\mathrm{G}$ ) and ACT (D and H). For relative representations, the expression levels at " $1 \mathrm{~cm}$ fruit" and "orange fruit" stages were adjusted to 1 for $F U L 1$ and $A P 2 c$, respectively (arrows). Error bars represent the standard error of the mean. 

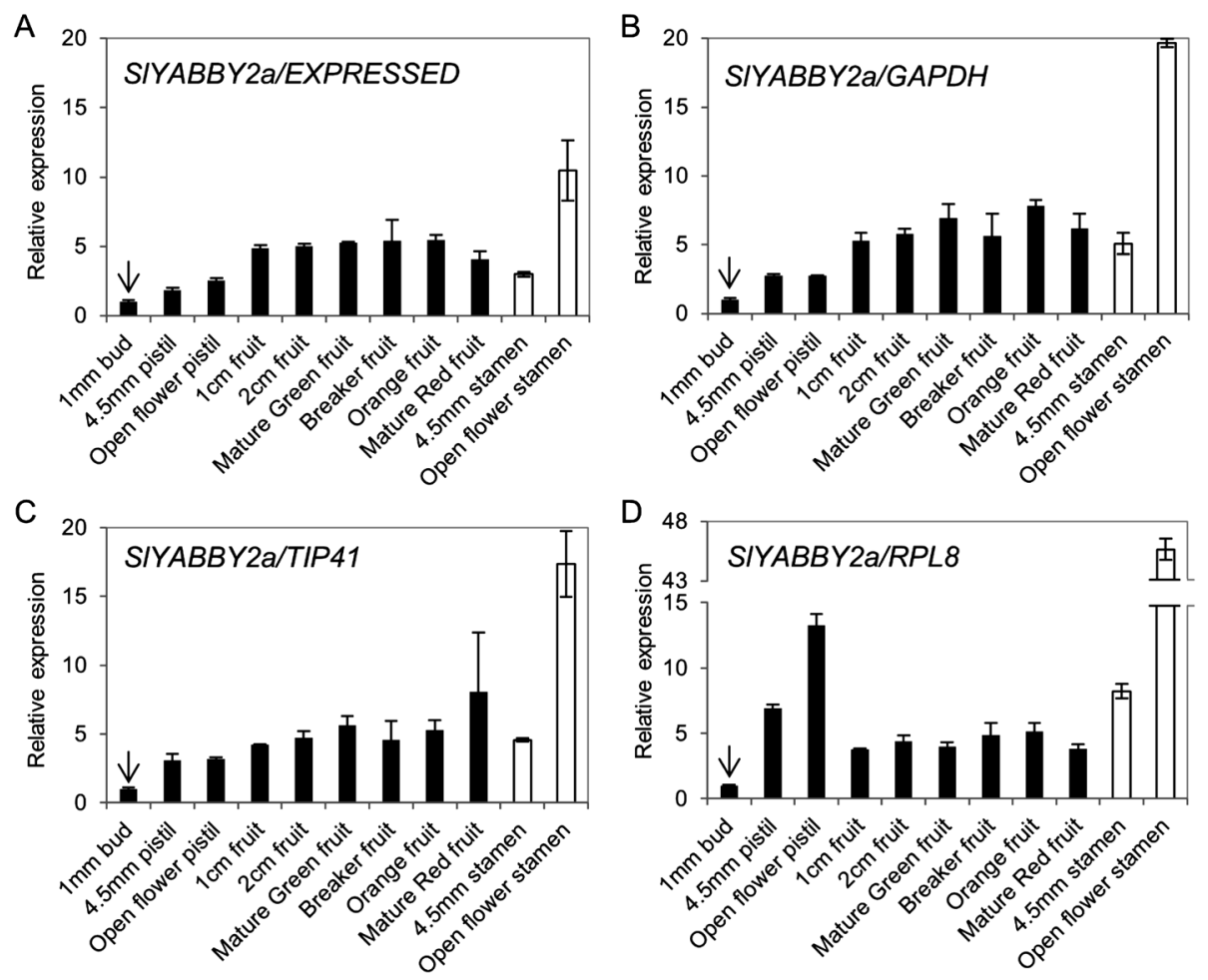

Figure 6. Expression profile of SlYABBY2a in flower and fruit datasets normalized against EXPRESSED (A), GAPDH (B), TIP41 (C) and RPL8 (D). For relative representations, the expression levels at " $1 \mathrm{~mm}$ bud" (arrows) were adjusted to 1 . White bars indicate the expression of $S l Y A B B Y 2 a$ in stamens. Error bars represent the standard error of the mean.

(Figure 6C; unstable candidate in fruit sample group) and RPL8 (Figure 6D; unstable candidate in flower sample group), the expression level of SlYABBY2a was overestimated in mature red fruit, and open flower stamen, respectively.

\section{Conclusion}

qRT-PCR is a simple and easy method to analyze expression of genes of interest in wide range of tissue samples collected from different developmental stages. In this study, we investigated and suggested the suitable internal control genes to analyze gene expressions in reproductive organs of dwarf tomato cultivar, MicroTom. To allow spatiotemporal profiling of gene expressions, we collected samples from 17 different reproductive tissues at different developmental stages, including leaf as a representative vegetative tissue. Among the eight commonly studied housekeeping genes, EXPRESSED was characterized as a reliable internal control gene for our sample groups. EXPRESSED was also reported as a remarkable internal control gene to analyze gene expressions in other tomato cultivars including Ciliegia, Santa Clara, Moneymaker, and MTRg1 (Expósito-Rodríguez et al. 2008; González-Aguilera et al. 2016; Lacerda et al. 2015). We also suggested that EXPRESSED and RPL8 were the optimal internal controls to analyze gene expression in developing fruits.
However we must keep in mind that the expression of RPL8 was unstable in tissues other than fruits. Thus, we also suggested that other internal controls such as TIP41 or GAPDH should also be utilized to obtain reliable data from samples including floral tissues. Indeed, our evaluation indicated that $G A P D H$ was also a usable internal control gene for monitoring the expression profiles through fruit developing starting from flowers. This is the first and sound report representing the credible internal control genes for qRT-PCR analysis in broad range of samples.

\section{Acknowledgements}

Tomato seeds (TOMJP00001) were provided by the University of Tsukuba, Gene Research Center, through the National BioResource Project (NBRP) of the Japan Agency for Research and Development (AMED), Japan. This work was supported by Cooperative Research Grant of the Plant Transgenic Design Initiative (PTradD) by Gene Research Center, Tsukuba-Plant Innovation Research Center, University of Tsukuba (16A1-15, 17A14, 18A-16 for E.I.), Kato Memorial Bioscience Foundation, and the Building of Consortia for the Development of Human Research in Science and Technology, MEXT, Japan. We thank all the members of our lab for their fruitful discussion of this paper.

\section{References}

Alvarez J, Smyth DR (1999) CRABS CLAW and SPATULA, two Arabidopsis genes that control carpel development in parallel 
with AGAMOUS. Development 126: 2377-2386

Andersen CL, Jensen JL, Ørntoft TF (2004) Normalization of realtime quantitative reverse transcription-PCR data: A modelbased variance estimation approach to identify genes suited for normalization, applied to bladder and colon cancer data sets. Cancer Res 64: 5245-5250

Argyropoulos D, Psallida C, Spyropoulos CG (2006) Generic normalization method for real-time PCR. Application for the analysis of the mannanase gene expressed in germinating tomato seed. FEBS J 273: 770-777

Bemer M, Karlova R, Ballester AR, Tikunov YM, Bovy AG, Wolters-Arts M, Rossetto PB, Angenent GC, de Maagd RA (2012) The tomato FRUITFULL homologs TDR4/FUL1 and MBP7/FUL2 regulate ethylene-independent aspects of fruit ripening. Plant Cell 24: 4437-4451

Brunner AM, Yakovlev IA, Strauss SH (2004) Validating internal controls for quantitative plant gene expression studies. BMC Plant Biol 4: 14

Bustin SA (2000) Absolute quantification of mRNA using real-time reverse transcription polymerase chain reaction assays. $J \mathrm{Mol}$ Endocrinol 25: 169-193

Bustin SA (2002) Quantification of mRNA using real-time reverse transcription PCR (RT-PCR): Trends and problems. J Mol Endocrinol 29: 23-39

Czechowski T, Stitt M, Altmann T, Udvardi MK, Scheible WR (2005) Genome-wide identification and testing of superior reference genes for transcript normalization in Arabidopsis. Plant Physiol 139: 5-17

Dekkers BJW, Willems L, Bassel GW, Van Bolderen-Veldkamp RP, Ligterink W, Hilhorst HWM, Bentsink L (2012) Identification of reference genes for RT-qPCR expression analysis in arabidopsis and tomato seeds. Plant Cell Physiol 53: 28-37

Expósito-Rodríguez M, Borges AA, Borges-Pérez A, Pérez JA (2008) Selection of internal control genes for quantitative realtime RT-PCR studies during tomato development process. BMC Plant Biol 8: 131

Ezura K, Ji-Seong K, Mori K, Suzuki Y, Kuhara S, Ariizumi T, Ezura H (2017) Genome-wide identification of pistil-specific genes expressed during fruit set initiation in tomato (Solanum lycopersicum). PLoS One 12: e0180003

Freeman WM, Walker SJ, Vrana KE (1999) Quantitative RT-PCR: pitfalls and potential. Biotechniques 26: 112-122, 124-125

Gachon C, Mingam A, Charrier B (2004) Real-time PCR: What relevance to plant studies? J Exp Bot 55: 1445-1454

Golz JF, Hudson A (1999) Plant development: YABBYs claw to the fore. Curr Biol 9: R861-R863

González-Aguilera KL, Saad CF, Chávez Montes RA, Alves-Ferreira M, de Folter S (2016) Selection of reference genes for quantitative real-time RT-PCR studies in tomato fruit of the genotype MTRg1. Front Plant Sci 7: 1386

Gutierrez L, Mauriat M, Pelloux J, Bellini C, Van Wuytswinkel O (2008) Towards a systematic validation of references in real-time RT-PCR. Plant Cell 20: 1734-1735

Hileman LC, Sundstrom JF, Litt A, Chen M, Shumba T, Irish VF (2006) Molecular and phylogenetic analyses of the MADS-box gene family in tomato. Mol Biol Evol 23: 2245-2258

Hong SM, Bahn SC, Lyu A, Jung HS, Ahn JH (2010) Identification and testing of superior reference genes for a starting pool of transcript normalization in Arabidopsis. Plant Cell Physiol 51: 1694-1706

Huang Z, Van Houten J, Gonzalez G, Xiao H, Van Der Knaap E (2013) Genome-wide identification, phylogeny and expression analysis of SUN, OFP and YABBY gene family in tomato. Mol Genet Genomics 288: 111-129

Huggett J, Dheda K, Bustin S, Zumla A (2005) Real-time RT-PCR normalization: Strategies and considerations. Genes Immun 6: 279-284

Karlova R, Rosin FM, Busscher-Lange J, Parapunova V, Do PT, Fernie AR, Fraser PD, Baxter C, Angenent GC, de Maagd RA (2011) Transcriptome and metabolite profiling show that APETALA $2 a$ is a major regulator of tomato fruit ripening. Plant Cell 23: 923-941

Lacerda ALM, Fonseca LN, Blawid R, Boiteux LS, Ribeiro SG, Brasileiro ACM (2015) Reference gene selection for qPCR analysis in tomato-bipartite begomovirus interaction and validation in additional tomato-virus pathosystems. PLoS One 10: e0136820

Libus J, Štorchová H (2006) Quantification of cDNA generated by reverse transcription of total RNA provides a simple alternative tool for quantitative RT-PCR normalization. Biotechniques 41: $156-164,158,160$ passim

Løvdal T, Lillo C (2009) Reference gene selection for quantitative real-time PCR normalization in tomato subjected to nitrogen, cold, and light stress. Anal Biochem 387: 238-242

Mascia T, Santovito E, Gallitelli D, Cillo F (2010) Evaluation of reference genes for quantitative reverse-transcription polymerase chain reaction normalization in infected tomato plants. $\mathrm{Mol}$ Plant Pathol 11: 805-816

Müller OA, Grau J, Thieme S, Prochaska H, Adlung N, Sorgatz A, Bonas U (2015) Genome-wide identification and validation of reference genes in infected tomato leaves for quantitative RTPCR analyses. PLoS One 10: e 0136499

Saito T, Ariizumi T, Okabe Y, Asamizu E, Hiwasa-Tanase K, Fukuda N, Mizoguchi T, Yamazaki Y, Aoki K, Ezura H (2011) TOMATOMA: A novel tomato mutant database distributing Micro-Tom mutant collections. Plant Cell Physiol 52: 283-296

Shikata M, Hoshikawa K, Ariizumi T, Fukuda N, Yamazaki Y, Ezura H (2016) TOMATOMA Update: Phenotypic and metabolite information in the Micro-Tom mutant resource. Plant Cell Physiol 57: e11

Thellin O, Zorzi W, Lakaye B, De Borman B, Coumans B, Hennen G, Grisar T, Igout A, Heinen E (1999) Housekeeping genes as internal standards: Use and limits. J Biotechnol 75: 291-295

Vandesompele J, De Preter K, Pattyn F, Poppe B, Van Roy N, De Paepe A, Speleman F (2002) Accurate normalization of real-time quantitative RT-PCR data by geometric averaging of multiple internal control genes. Genome Biol 3: RESEARCH0034

Villanueva JM, Broadhvest J, Hauser BA, Meister RJ, Schneitz K, Gasser CS (1999) INNER NO OUTER regulates abaxial- adaxial patterning in Arabidopsis ovules. Genes Dev 13: 3160-3169 